J. Indian Chem. Soc.,

Vol. 82, December 2005, pp. 1103-1111

\title{
Green chemistry in sustainable national development $\psi$
}

\author{
M. Kidwai* and R. Thakur \\ Department of Chemistry, University of Delhi, Delhi-110 007, India \\ E-mail : kidwai_chemistry@yahoo.co.uk_ Fax : 91-11-27666235
}

Manuscript received 6 June 2005

\begin{abstract}
The green chemistry revolution provides an enormous number of oppourtunities to discover and apply new synthetic approaches using alternative feedstocks; ecofriendly reaction conditions, energy minimizations and the design of less toxic and inherently safer chemicals. The origin and basis of green chemistry chart for achieving environmental and economic prosperity inherent in a sustainable world. One important element of sustainable chemistry is commonly defined as the chemical research aiming at the optimization of chemical processes and products with respect to energy and material consumption, inherent safety, toxicity, environmental degradability, and so on. While considerable progress has been made in environmental chemistry, green chemistry, and the environmental assessment of chemical products but the societal aspect of sustainable chemistry remains to be recognized fully in all branches of chemical research, one prerequisite for this is the inclusion of sustainable chemistry into chemical education from the very beginning.
\end{abstract}

\section{Definition}

Green Chemistry (environmentally benign chemistry) is the utilization of set of principles that reduces or eliminates the use or generation of hazardous substances in the design, manufacture and application of chemical products. In practice, green chemistry is taken to cover a much broader range of issues than the definition suggests ${ }^{1}$. As well as using and producing better chemicals with less waste, green chemistry also involves reducing other associated environmental impacts ${ }^{2}$, including reduction in the amount of energy used in chemical processes. Green Chemistry is not different from traditional chemistry in as much as it embraces the same creativity and innovation that has always been central to classical chemistry. However, there lies a difference in that historically synthetic chemists have not been seen to rank the environment very high in their priorities. But with an increase in environmental consciousness throughout the world, there is a challenge for chemists to develop new products, processes and services that achieve necessary social, economical and environmental objectives. Since the types of chemicals and the types of transformations are much varied, so are the green chemistry solutions that have been proposed. Anastas and Warner ${ }^{3}$ (1998) developed 'The Twelve Principles of Green Chemistry' that serve as guidelines for practising chemists in developing and assessing how green a syththesis, compound, process or technology is.

\section{Industrial interest in Green Chemistry}

Many forward-looking companies are embracing green chemistry, not only to protect the environment and to create good public relations, but also because it is often beneficial to the bottom line 4,5 . It is estimated to cost US industries between $\$ 100$ and $\$ 150$ billion per year the comply to environmental regulations ${ }^{6}$. In addition, cleaning up hazardous waste sites will cost hundreds of billion of dollars. In many companies, the cost of dealing with environmental regulations often exceeds their expenditures for research. Larger companies budget close to $\$ 1$ billion per year for environmental compliance. If a company can significantly reduce these expenditures, then these funds can be spent in more productive areas and result in an improved bottom line. Thus, green chemistry (pollution prevention) is not only good for the environment but also for industry.

\section{Green Chemistry in Education}

Convincing chemists to think in an environmentally friendly manner begins with education. The idea of including green chemistry in chemistry cducation was first put forward in $1994^{7}$. A complete course was described shortly thereafter ${ }^{8}$. Few green chemistry textbooks have also been published ${ }^{3,9}$. Graduates, post-graduates, teachers and researchers will find these books of immense use. Both EPA and ACS have recognized the importance of bringing green chemistry to the classroom and the labo-

\footnotetext{
${ }^{\Psi}$ Dedicated to Professor H. C. Gaur on his 80 th birthday.
} 
ratory. Together they have launched a significant campaign to develop a green chemistry educational materials and to encourage the greening of the chemistry curricu$\operatorname{lum}^{10,11}$.

Student involvement in Green Chemistry principles and practices is essential to the integration of environmentally benign technologies in academia and industry. ACS Student Affiliate Chapters may be recognized as a "green" chapter by engaging in atleast three green chemistry activities during the academic year. Suggestions for such activities include :

- Hosting a green chemistry speaker.

- Organizing an interdisciplinary green chemistry workshop on campus.

- Working with a local company on a green chemistry project.

- Developing a Green Chemistry activity with a local school.

- Converting a current lab experiment into a greener one.

- Organizing a Green Chemistry poster sessions on campus.

- Distributing a Green Chemistry Newsletter to the local community.

- Designing a Green Chemistry web-page.

\section{Atom efficiency}

One of the key ideas of green chemistry is that of atom economy. The concept of atom economy as developed by Barry Trost considers how much of the reactants in a chemical reaction ends up in the final useful product or products. With selectivity and yield being the prime concern in the areas of fine chemicals, pharmaceuticals and academics, the efficient use of reactants from the standpoint of atom economy is often ignored ${ }^{12,13}$. When these reactants are used inefficiently their atoms wind up, in part, as waste byproducts of the reaction. The goal of atom economy is to create syntheses in which most of the atoms of the reactants become incorporated into the desired final product leading to fewer waste byproducts ${ }^{14}$.

The concept of atom economy was quantified by Sheldon ${ }^{15}$ (Professor at Delft University in the Netherlands). He calculated percentage atom utilization by dividing the molecular weight of the desired product by the molecular weights of all the products generated in a reaction (Formula 1).

$$
\% \text { Atom utilization }=\frac{\text { Molecular weight of desired product }}{\text { Molecular weight }} \times 100
$$

Formula 1

However, in many reactions the identities of waste by products are unknown or difficult to determine. Fortunately, conservation of mass can be used to calculate a number similar to the percentage atom utilization called the percentage atom economy by totaling the formula weight (FW) of all the atoms in the reactants that are incorporated into the final products and divide this number by the total formula weight of all the reactants (Formula 2).

$\%$ Atom economy $=\frac{\text { Formula weight of atoms utilized }}{\text { FW of all reactants used in the reaction }} \times 100$

Formula 2

When we look at some common organic reactions (rearrangement, addition, substitution and elimination) we find that the rearrangement and addition reactions tend to be most atom economical (100\%), followed by substitution $(65.41 \%)$ and the least economical being the elimination reaction $(35.30 \%)$ (Schemes $1-4)$.

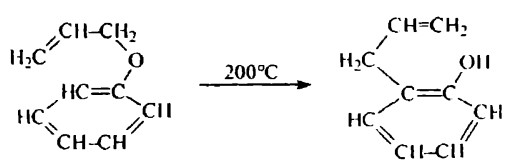

$\%$ Atom economy $=\frac{134.175}{134.175} \times 100=100 \%$

Scheme 1. Claisen rearrangement.

$$
\begin{aligned}
& \mathrm{H}_{3} \mathrm{C}-\mathrm{CH}=\mathrm{CH}_{2}+\mathrm{H}_{2} \stackrel{\mathrm{Ni}}{\longrightarrow} \mathrm{H}_{3} \mathrm{C}-\mathrm{CH}_{2}-\mathrm{CH}_{3} \\
& \text { \% Atom economy }=\frac{44.096}{44.096} \times 100=100 \%
\end{aligned}
$$

Scheme 2. Addition reaction.

$$
\begin{aligned}
& \mathrm{H}_{3} \mathrm{C} \stackrel{\mathrm{O}}{\mathrm{O}}_{\text {\% Atom economy }}=\frac{87.120}{133.189} \times 100=65.41 \%
\end{aligned}
$$

Scheme 3. Substitution reaction. 
Kidwai et al. : Green chemistry in sustainable national development

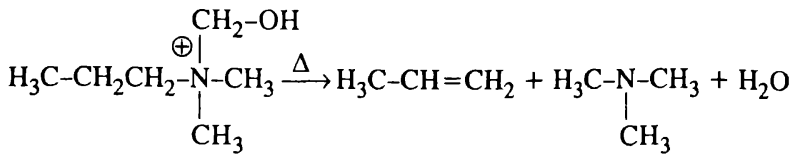

$\%$ Atom economy $=\frac{42.080}{119.205} \times 100=35.30 \%$

Scheme 4. Elimination reaction.

Many atom economical reactions using various transition metal catalysts have been developed ${ }^{16,17}$. The synthesis of rosefuran ${ }^{18}$ (Scheme 5) performed using metal transition complexes in catalytic cycle, is example of an atom economic process proceeding with very high yield and substantial waste reduction. The concept of atom economy has also been employed by the Shell corporation to make methyl methacrylate (Scheme 6) ${ }^{19}$. The old synthesis (Scheme 7) manifests only $47 \%$ atom economy due to the use of stoichiometric amounts of hydrogen cyanide and sulfuric acid whereas the new synthesis (Scheme 6), which employs a palladium catalyst, enjoys $100 \%$ atom economy. Recently many classical routes for chemical synthesis are being replaced by catalytic processes $^{20}$. Scheme 8 compares the synthesis of acetophenone by classical oxidation of l-phenylethanol using stoichiometric amounts of chromium oxide and sulfuric acid, resulting in an atom efficiency of $42 \%$, with the heterogeneous catalytic oxidation with $\mathrm{O}_{2}$, having an atom efficiency of $87 \%$ and resulting in water as the only byproduct. The increasing use of catalytic processes can substantially reduce waste at the source resulting in primary pollution prevention.

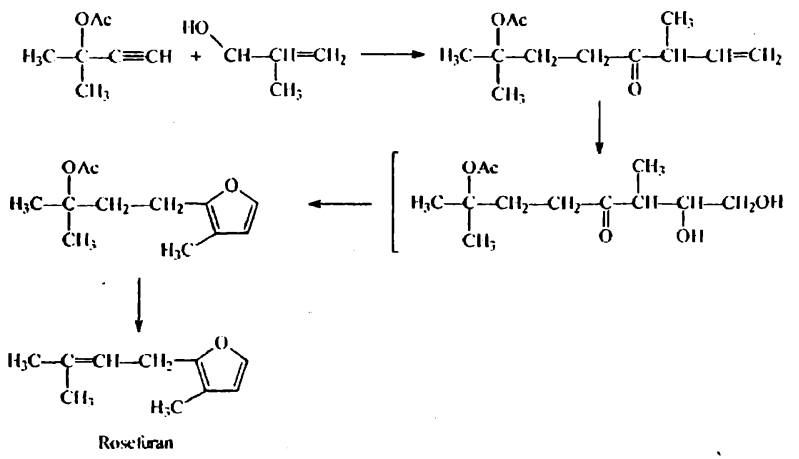

Scheme 5

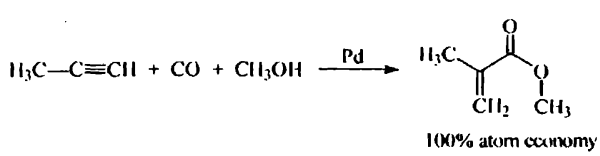

Scheme 6

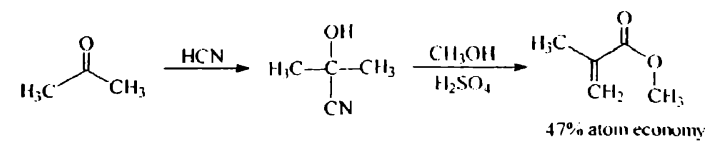

Scheme 7

$$
\begin{aligned}
& 3 \mathrm{PhCH}(\mathrm{OH}) \mathrm{CH}_{3}+2 \mathrm{CrO}_{3}+ 3 \mathrm{H}_{2} \mathrm{SO}_{4} \longrightarrow \\
& 3 \mathrm{PhCOCH}_{3}+\mathrm{Cr}_{2}\left(\mathrm{SO}_{4}\right)_{3}+6 \mathrm{H}_{2} \mathrm{O}
\end{aligned}
$$

Stoichiometric oxidation

$$
\begin{gathered}
\mathrm{PhCH}(\mathrm{OH}) \mathrm{CH}_{3}+1 / 2 \mathrm{O}_{2} \longrightarrow \mathrm{PhCOCH}_{3}+\mathrm{H}_{2} \mathrm{O} \\
\text { Catalytic oxidation }
\end{gathered}
$$

Scheme 8

\section{Energy conservation}

Energy generation and consumption has long been known to produce a major environmental effect. Chemistry and chemical transformations play a major role in capturing and converting substances into energy as well as converting existing sources of energy into a form that is usable to society. Microwave irradiation in the solid state $^{21}$ is a technique that is being utilized to effect chemical transformations rapidly, in contrast to those that have classically been conducted in liquid solutions. Solventfree microwave assisted reactions ${ }^{22}$ provide an opportunity to work with open vessels thus avoiding the risk of high pressure and increasing the potential for scale up of such reactions. The practical feasibility of microwave assisted solvent free synthesis has been demonstrated in various useful transformations ${ }^{23-25}$ and in the synthesis of heterocyclic systems ${ }^{26-28}$ (Schemes 9-11). The microwave technique has shown distinct advantages in not requiring prolonged heating to carry out a reaction.

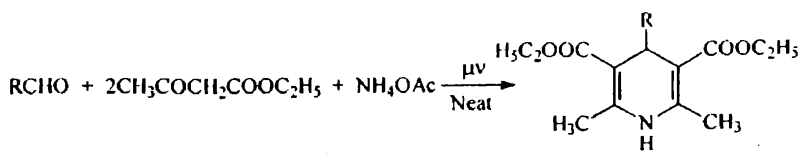

Scheme 9

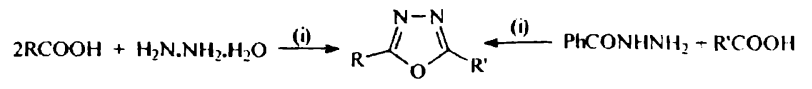

(i) acidic ahunina or Montnorillonite $\mathrm{K}_{10} \mathrm{Chy} / \mathrm{MW} /$

Scheme 10

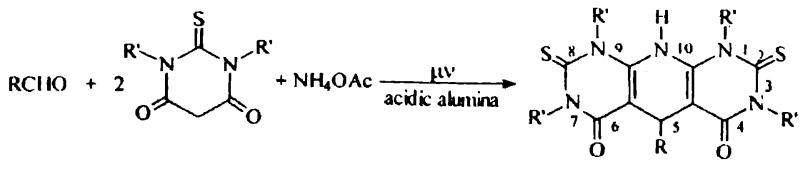

Scheme 11 
Ultrasound is a relatively new way of introducing energy into chemical systems ${ }^{29}$. It has been used to enhance reaction rates ${ }^{30}$ in a large number of classical organic reactions (Scheme 12). Though the use of phase transfer catalysts in organic aqueous biphasic systems is well known to catalyse heterogeneous liquid-liquid reactions, ultrasound is much more effective in these reactions because ultrasonic waves generate extremely fine emulsions which results in very large interfacial contact areas between the liquids and a corresponding dramatic increase in the reactivity between dissolved species (Scheme 13).

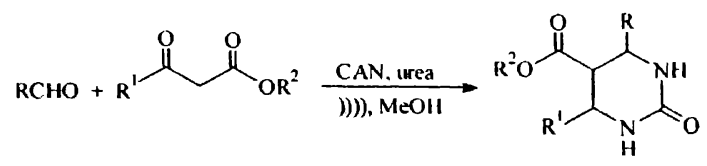

Scheme 12

$$
\mathrm{CH}_{2}=\mathrm{CHCH}_{2} \mathrm{Cl} \underset{88 \%,()))))}{\stackrel{\mathrm{NaN}_{3} / \mathrm{H}_{2} \mathrm{O}}{\longrightarrow}} \mathrm{CH}_{2}=\mathrm{CHCH}_{2} \mathrm{~N}_{3}
$$

\section{Scheme 13}

The problems associated with waste disposal of solvents and excess chemicals has been overcome by performing reactions without solvent under microwave irradiation (MWI) or ultrasound. Heterogeneous organic reactions have also proven useful to chemists. These reactions are effected by the reagents immobilized on the porous solid supports and have advantages over the conventional solution phase reactions because of good dispersion of active reagent sites, associated selectivity and easier work up.

\section{Green alternatives}

Two of the main components of chemical synthesis are feedstocks and reaction conditions : either or both of these may be changed to produce alternative or improved chemical syntheses. With advances in biotechnology, biocatalysis and biosynthesis there have been significant accomplishments in the use of biologically based feedstocks/raw materials as a viable alternative to petroleum feedstocks for a number of chemical processes ${ }^{31}$. The selection of feedstocks has a major effect, not only on the efficacy of the synthetic pathway, but also on the environmental and health effects of the process. Like many chemicals, adipic acid, catechol and BHT are produced using petroleum-based starting materials, namely benzene and toluene. Draths and Frost ${ }^{32,33}$ have developed a biosynthetic method to produce adipic acid, catechol and DHS from glucose in place of benzene using genetically altered E. coli (Scheme 14). This biosynthetic pathway can help to minimize the use of certain reagents with significant toxicity.

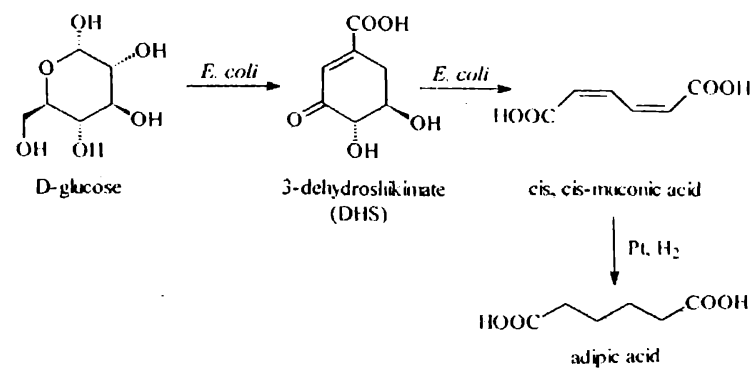

Scheme 14

\section{Reagents :}

In particular, an underdeveloped area of chemistry involves the replacement of reagents which are toxic, dangerous, produced by eco-unfriendly processes and not selective. In order to carry out the transformation of selected feedstocks into the target molecule, the criteria efficiency, availability and effect of the reagent used must be kept in mind. Examples of undesirable reagents used for methylation and carbomethylation are methyl halides $\left(\mathrm{CH}_{3} \mathrm{X}\right)$, dimethylsulfate (DMS) and phosgene. These toxic and waste producing reagents have a valuable green alternative i.e. dimethylcarbonate (DMC). Tundo ${ }^{34}$ has used DMC as an environmentally benign substitute for DMS and $\mathrm{CH}_{3} \mathrm{X}$ in methylation reactions (Scheme 15). The traditional synthesis of polyurethanes requires the use of phosgene, an extremely toxic gas. The Monsanto company has developed a method of synthesizing polyurethanes that totally eliminates the use of phosgene ${ }^{35}$ (Scheme 16).

$$
\mathrm{PhOH}+\mathrm{CH}_{3} \mathrm{OCOOCH} \mathrm{Cat}_{3} \stackrel{\text { Cat. base }}{\longrightarrow} \mathrm{PhOH}_{3}+\mathrm{CO}_{2}+\mathrm{CH}_{3} \mathrm{OH}
$$

Scheme 15

$$
\begin{gathered}
\mathrm{RNH}_{2}+\mathrm{CO}_{2} \longrightarrow \mathrm{RNCO}+\mathrm{H}_{2} \mathrm{O} \stackrel{\mathrm{R}^{\prime} \mathrm{OH}}{\longrightarrow} \mathrm{RNHCOOR}^{\prime} \\
\text { Scheme } 16
\end{gathered}
$$

$\mathrm{K}_{2} \mathrm{CO}_{3}$ has been used as a green reagent ${ }^{36,37}$ for the synthesis of various heterocyclic compounds (Schemes 17-19). The usage of $\mathrm{K}_{2} \mathrm{CO}_{3}$ not only eliminates the requirement of solvent from reaction stage but work up requires only water. Also $\mathrm{K}_{2} \mathrm{CO}_{3}$ serves as a base, eliminating the need for an external base.

Solvents : 
Kidwai et al. : Green chemistry in sustainable national development

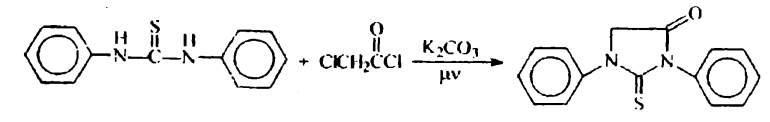

Scheme 17

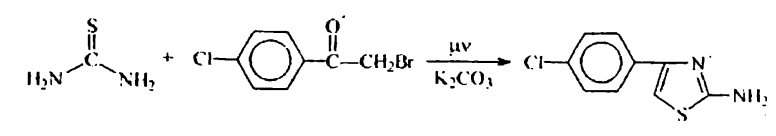

Scheme 18

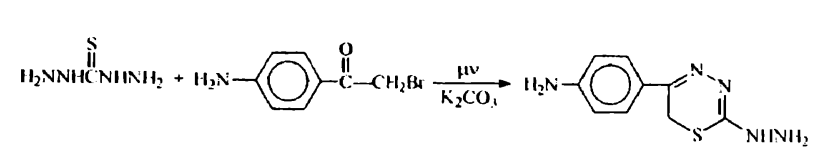

Scheme 19

An important area of green chemistry investigations has centered around the selection of a medium in which to carry out a synthetic transformation. Many of the solvents commonly used are volatile organic compounds known to cause smog when released in air. These solvents are listed in the United States' Clean Air Act as substances to be avoided. There has been an increased emphasis, both in the chemical industry and academic research on development of environmentally benign solvents. While traditional solvents are well known, alternatives such as ionic liquids and supercritical fluids are increasingly being applied in synthesis. Usage of supercritical fluids, such as carbon dioxide, nut only obviate waste disposal problems but also offer other advantages $^{38}$ such as controlling the phase behaviour of products, increasing reaction rates and providing better efficiency. Supercritical carbon dioxide ${ }^{39}$ has been employed in the synthesis of organometallic compounds, metal chelation, extractions, preparation of nanoparticles and lipase-catalysed reactions.

As a result of the compelling need for industry to consider the reengineering of entire processes, ionic liquids have begun to receive worldwide academic and industrial attention ${ }^{40}$. Ionic solvents provide a unique opportunity for science/engineering/business to work together from the beginning of a field's development and thus lead more quickly to innovative environmentally and economically sustainable industrial processes. General advantages of ionic solvents are that they have no measurable vapour pressure, are thermally robust, will tolerate impurities such as water and if the extraction solvent is recycled, generate almost no waste product.

'Neat critical' water offers outstanding performance as a benign solvent for both organic and ionic compounds ${ }^{41}$. Conventionally, Friedel-Crafts acylations require the presence of Lewis acids such as aluminium chloride, ferric chloride and zinc chloride. But in near critical water, phenol could be converted with acetic acid to produce 2'-hydroxyacetophenone, 4'-hydroxyacetophenone and phenyl acetate without the addition of an acid catalyst (Scheme 20).

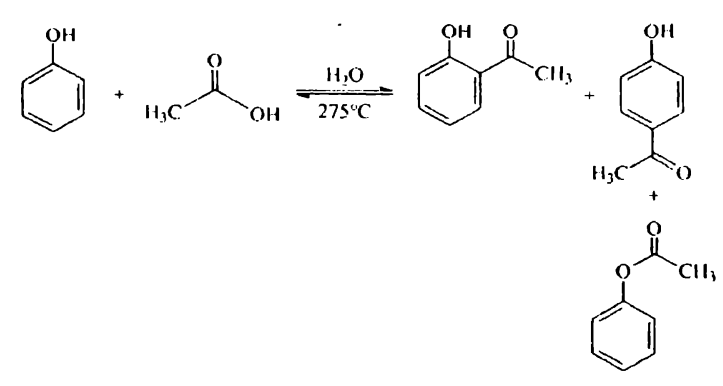

Scheme 20

\section{Catalyst :}

Some of the major advances in chemistry, especially industrial chemistry, over the past generation have been in the area of catalysts. Through the use of catalyst, chemists have found ways of removing the need for large quantities of reagents that would otherwise have been needed for chemical transformation and would ultimately have contributed to the waste stream. For example, the traditional catalyst hydrogen fluoride, an extremely corrosive, hazardous and toxic chemical used in the production of linear alkylbenzenes (LAB's), has been successfully replaced by a solid acid catalyst, viz. fluorided silica-alumina catalyst, which does not require special construction materials, involves lower operating costs and obviates the need for waste disposal of calcium fluoride ${ }^{3}$.

Biocatalytic transformations represent an immense potential in organic synthesis. Enzymes occupy a prominent place among biocatalysts and have a wide spectrum of biotechnological applications ${ }^{42}$. The stability of enzymes in organic solvents have pushed them into the frontier areas of organic synthesis ${ }^{43}$.

An environmentally friendly and safe method developed for preparation of 3-carbamoyl cephalosporin derivatives, such as cefuroxime and its prodrug ester, cefuroxime axetil uses o-transcarbamoylase, an enzyme of microbial origin for the conversion of the 3-hydroxy function to the desired 3-carbamoyl group. This new synthesis replaces the conventional chemical roate, that em- 
ploys hazardous isocyanates such as dichlorophosphinyl isocyanate or chlorosulfinyl isocyanate ${ }^{44}$ to achieve the same conversion (Scheme 21).

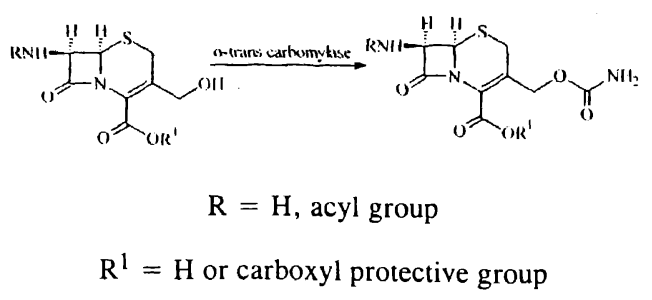

Scheme 21

More than $90 \%$ of all processes in the chemical and petrochemical industry as well as in refinery technology are mainly heterogeneously catalyzed processes. A large number of industrial process which are catalyzed by solid acid, base and acid base bifunctional catalysts are known. Zeolites themselves account for more than $40 \%$ of the acid-base catalysts. As an example, isobutene reacts with ammonia over pentasil zeolites at $300^{\circ} \mathrm{C}$ and 300 bar to give excellent results ${ }^{45}$ (Scheme 22).

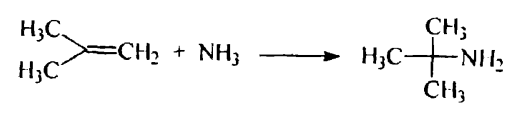

Scheme 22

Phase transfer catalyst (PTC) :

The PTC methodology is applicable to a great variety of reactions in which inorganic and organic anions and also carbenes react with organic substrates. PTC in liquid-solid systems is often used for synthesis and manufacturing of esters of carboxylic acids via reaction of solid sodium or potassium carboxylates with alkyl halides $^{46}$ (Scheme 23).

$$
\mathrm{Cl}\left(\mathrm{CH}_{2}\right)_{5} \mathrm{Cl}+\mathrm{HCOONa} \stackrel{\mathrm{TBAB}}{\longrightarrow} \mathrm{OHC}-\mathrm{O}-\left(\mathrm{CH}_{2}\right)_{5} \mathrm{O}-\mathrm{CHO}
$$

\section{Scheme 23}

While a synthesis is often driven by the pursuit of a particular target, with pharmaceuticals, the object is to maximize the therapeutic benefits of a molecule while minimizing or eliminating the toxic side effects. In cases where function is the primary motive, molecular manipulation that preserves efficacy of function by mitigating toxicity or other hazards is the goal of green chemistry. Through these efforts and other toxicological research, it is often possible to identify the part or parts of a molecule that produce toxic effects. An example of how one can assess the toxicological consequences of a particular functional group and then use this information to design inherently safer compounds has been described by De Vito $^{47}$ who compared the toxicity of 3-hydroxypropionitrile vs 2-hydroxypropionitrile (Fig. 1).

$$
\begin{array}{cc}
\underbrace{\mathrm{CH}_{2}-\mathrm{CH}_{2}-\mathrm{CN}}_{\mathrm{OH}} & \text { H }_{3}^{\mathrm{C}-\mathrm{CH}-\mathrm{CN}} \\
\text { 3-Hydroxypropionitrile } & \text { 2-Hydroxypropionitrile } \\
\text { rat oral } \mathrm{LD}_{50}=45 \mathrm{mmol} / \mathrm{kg} & \text { rat oral } \mathrm{LD}_{50}=1.23 \mathrm{mmol} / \mathrm{kg}
\end{array}
$$

Fig. 1

Toxicological studies demonstrate that the 2-hydroxy isomer is much more toxic than the 3-hydroxy isomer. The mechanism of acute toxicity is proposed to be elimination of hydrogen cyanide from the cyanohydrin. Depending on the nature of the substitution at the $\alpha$-carbor. position, this elimination can be accelerated or slowed down. Knowing this, new propionitriles can be designed to reduce this mechanistic pathway and thus be inherently safer ${ }^{48}$. Reacting aryl acetonitriles with dimethyl carbonate at $180-220^{\circ} \mathrm{C}$ in presence of $\mathrm{K}_{2} \mathrm{CO}_{3}$ produces 2 -aryl propionitriles with high selectivity $(>90 \%)$. In this process no inorganic salts are produced (Scheme 24).

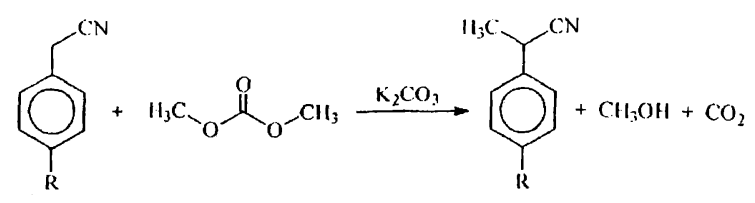

Scheme 24

\section{Sustainable Chemistry : Starting points and prospects}

Sustainability is significantly determined by how we manipulate matter within the economy, the inventive leadership of chemists is vital to its future ${ }^{49}$ sustainable chemistry should also address the societal aspect of sustainability, with respect to scientific research, the societal aspect is designed by two requirements :

(1) The assumptions, objectives and implication of chemical research and its technical application should be made more transparent to various societal actors.

(2) Uncertainity and ignorance should be treated more explicitly in the course of scientific research. 
Kidwai et al. : Green chemistry in sustainable national development

\section{Current status}

Since 1991, green chemistry has grown into a significant internationally engaged focus area within chemistry. Research programs and centres located in America, Europe, Asia/Pacific and Africa are focusing efforts around the principles of green chemistry ${ }^{50}$. The breadth of this research is very wide and incorporates area such as

(I) Bio-based renewables

(II) Green engineering education for sustainability for developing countries

(III) Compressed $\mathrm{CO}_{2}$ an environmentally friendly solvent

(I) Bio-based renewables :

The utilization of benign, renewable feed stocks is needed component of addressing the global depletion of resources. Bio-based products hold great promise for achieving the goals of sustainable development and implementing the principles of industrial ecological and green chemistry $^{51}$.

Achieving a sustainable chemical industry dictates switching from depleting finite sources to renewable feed stocks.

Research in this area has focused on both the macro and molecular levels.

(1) The carbohydrate economy provides a rich source of feed stock for synthesizing commodity 52 and for example :

Agricultural wastes $\longrightarrow$ Converted into

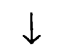

Useful chemical intermediates

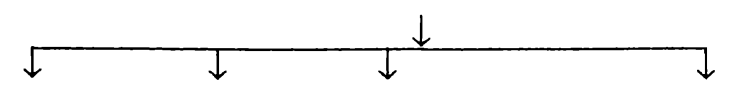

Alcohols Ketones Carboxylic acids Levuling acid

(2) Shells from crabs and other sea life serve as a valuable and plentiful source of chitin which can be processed into chitosan - a biopolymer with a wide range of potential applications that are being currently explored for use in the oil-drilling industry ${ }^{53}$.

(3) Genetic engineering produces valuable chemical products via nontraditional pathways.

(4) Glucose $\stackrel{\text { Yields }}{\longrightarrow}$ Catechol and adipic acid 54 .

(5) Saccharomyces yeasts convert both glucose and

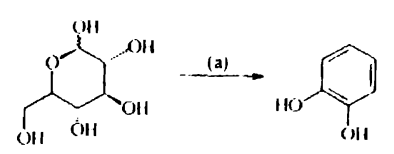

(a) E.coli $\mathrm{AB} 2834 / \mathrm{pKD} 136 / \mathrm{pKD} 9.069$ A. $37^{\circ} \mathrm{C}$

xylose, present in cellulosic biomass, into etha$\mathrm{nol}^{55}$.

(6) $\mathrm{CO}_{2}$ is also a renewable feedstock that has been incorporated into polymers ${ }^{56}$.

(II) Green engineering education for sustainability for developing countries :

Ujang et al. ${ }^{57}$ presented a paper of existing philosophy, approach, criteria and delivery of environmental engineering (EE) education $\left(E_{3}\right)$ for developing countries.

(1) In general EE is being taught in almost all major universities in developing countries, mostly under civil engineering degree programmes. The main component of $\mathrm{E}_{3}$ in near future will remain on basic sanitation in most developmg countries, with special emphasis on the consumer-demand approach.

(2) The concept, principles and methodologies of Green chemistry and Green engineering are fundamental in integrating sustainability ${ }^{51}$ throughout the system of our chemical enterprise. By incorporating these Green chemistry approaches in the research and development, scaleup and commercialization stages in industry and by ensuring that training of both established and next generation chemists and engineers includes Green chemistry and engineering, large strides can and are being made in sustainability in the chemical industry.

(3) In order to substantially overcome environmental problems in developing countries, $E_{3}$ should include integrated urban water management, sustainable sanitation, appropriate technology, cleaner production waste water minimisation and financial framework.

(III) Compressed $\mathrm{CO}_{2}$ an environmentally friendly solvent :

Many solvents are unpleasant but essential industrial chemicals. Supercritical $\mathrm{CO}_{2}$ would be a viable green alternative but its use has been restricted by its limited solvent power. This is about to change.

Phase diagram for $\mathrm{CO}_{2}$ 


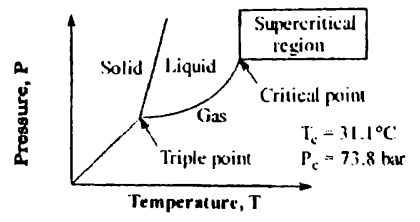

Beyond a specific temperature and pressure $\mathrm{CO}_{2}$ becomes a supercritical fluid, a state that is neither a gas nor a liquid, but has properties of both, known as critical point.

(1) The specific properties of $\mathrm{ScCO}_{2}$ make it an interesting "green" replacement for organic solvent which are often less than ideal owing to their acute toxicity, ecological hazards or difficulty with disposal and recycling.

(2) Supercritical $\mathrm{CO}_{2}\left(\mathrm{ScCO}_{2}\right)$ find applications in areas as diverse as the dyeing and cleaning of fibres and textiles polymerization and polymer processing, purification and crystallization of pharmaceuticals, and last but not the least as a reaction medium for chemical synthesis.

(3) Most widely used $\mathrm{CO}_{2}$ Philic solubilizer have been polysiloxanes and flurocarbons. The Beckman group ${ }^{58}$ has now synthesized a nonfluorous but still highly $\mathrm{CO}_{2}$-philic polymer, whose solubility in $\mathrm{ScCO}_{2}$ results from a judicious design.

(4) The target compound of the Beckman group was copolymer (polyether and polycarbonate group) such copolymers can be easily generated using an $\mathrm{Al}$-catalyst to react propylene oxide $\left(\mathrm{C}_{3} \mathrm{H}_{6} \mathrm{O}\right)$ with $\mathrm{CO}_{2}$ itself.

(5) Polyether skeleton is highly flexible and has only weak polymer-2 interactions, when carbonate group is introduced. It enhances this flexibility, and therefore the entropy of mixing. At the same time a favourable interaction of the carbonyl group with $\mathrm{CO}_{2}$ may increase the enthalpy of mixing, thereby also improving the solubility of these compounds in $\mathrm{CO}_{2}$.

\section{Conclusion :}

The growth of green chemistry over the course of the past decade needs to increase at an accelerated pace if molecular science is to meet challenges of sustainability. It has been said that the revolution of one day becomes the new orthodox of the next Green chemistry is applied and must involve the successful implementation of more environmentally friendly chemical processes and product design. Most importantly we need the relevant scientific, engineering, educational and other communities to work together for sustainable future through Green chemistry.

\section{References}

1. M. Lancaster, Green Chemistry, Education in Chemistry, 2000, 37, 2, 40 .

2. "Clean Technology for the Manufacture of Speciality Chemicals", eds. W. Hoyle and M. Lancaster, Royal Society of Chemistry, 2001.

3. P. Anastas and J. C. Warner, "Green Chemistry, Theory and Practice", Oxford University Press, 1998.

4. S. L. Wilkinson, "Green" is Practical, Even Profitable. No longer a luxury, Green Chemistry becomes a central strategy for sustainable firms, Chem. Eng. News, 1997, 75 (August 4), 35.

5. An editorial by then ACS President R. Breslow, Chem. Eng. News, 1996, 74 (August 26), 72.

6. http://www.epa.gov/opptintr/greenchemistry/presgcc.htm.

7. Chemical Educators Grapple with Environmental Focus for Undergraduates, Chem. Eng. News, 1994, 72 (April 4), 34.

8. T. Collins, J. Chem. Education, 1995, 72, 965.

9. V. K. Ahluwalia and M. Kidwai, "New Trends in Green Chemistry", Kluwer Academic Publishers, Norwell MA 02061, 2003.

10. ACS Green Chemistry Initiatives Get Boost from EPA Grant, Chem. Eng. News, 1998, 76(33), 47.

11. US Environmental Protection Agency. web-site : www.epa.gov/opptintr/greenchemistry/educat.htm.

12. M. C. Cann and M. E. Connelly, "Real World Cases in Green Chemistry", American Chemical Society, 2001.

13. B. M. Trost, Science, 1991, 254, 1471.

14. B. M. Trost, "Atom Economy - A Challenge for Organic Synthesis : Homogeneous Catalysis Leads the Way", Angewandte Chemie International Edition, 1995, 34, 259.

15. R. A. Shelden, "Organic Synthesis - Past, Present and Future", Chem. Ind. (London), December, 1992, 903.

16. B. M. Trost, Science, 1983, 219, 245.

17. B. M. Trost, F. D. Toste and H. Shen, J. Am. Chem. Soc., 2000, 22, 2379.

18. B. M. Trost and J. A. Flygare, J. Org. Chem., 1994, 59, 1078 .

19. R. A. Sheldon, "Catalysis and Pollution Prevention", Chemistry and Industry, 1997, 12.

20. B. M. Trost, 'A search for Atom Economy', Green Chemistry Series No. 1, Collection of Lectures : Summer Schools on Green Chemistry, ed. P. Tundo, Venice, 1998-1999-2000.

21. R. S. Varma, "Solvent-free Organic Synthesis : Using supported reagents and microwave irradiation", Green Chemistry, 1999, 1, 43. 
Kidwai et al. : Green chemistry in sustainable national development

22. M. Kidwai, Pure Appl. Chem., 2001, 73, 147.

23. M. Csiba, J. Cleophax, A. Loupy, J. Malthete and S. D. Gero, Tetrahedron Lett., 1993, 34, 1787.

24. R. S. Varma, R. K. Saini and R. Dhaiya, Tetrahedron Lett., 1997, 38, 7823.

25. D. Villemin and B. Martin, Synth. Commun., 1995, 25 , 3135 .

26. M. Kidwai, S. Saxena, R. Mohan and R. Venkataramanan, J. Chem. Soc., Perkin Trans. 1, 2002, 1845.

27. M. Kidwai and R. Mohan, Org. Prep. Proc. Int., 2003, 35,426 .

28. M. Kidwai, R. Mohan and S. Saxena, Russ. Chem. Bull. Int. Ed., 2003, 52, 2457.

29. J. M. Khurana, 'Sonochemistry', Chemistry Education, 1990, 24.

30. J. S. Yadav, B. V. S. Reddy, K. B. Reddy, K. S. Raj and A. R. Prasad, J. Chem. Soc., Perkin Trans. 1, 2000, 1939.

31. J. W. Frost and K. M. Draths, 'Sweetening Chemical Manufacture', Chemistry in Britain, 1995, 31(3),206.

32. K. M. Draths and J. W. Frost, J. Am. Chem. Soc., 1994, 116, 399.

33. K. M. Draths and J. W. Frost, J. Am. Chem. Soc., 1995, 117, 2395.

34. F. Trotta P. Tundo and G. Moraglio, J. Org. Chem., 1987, 52, 1300.

35. T. E. Waldman and D. P. Riley, J. Chem. Soc., Chem. Commun., 1994, 957.

36. M. Kidwai, R. Venkataramanan and B. Dave, 'Solventless Synthesis of Thiohydantoins over $\mathrm{K}_{2} \mathrm{CO}_{3}{ }^{\prime}$, Green Chemistry, 2001, 3, 278.

37. M. Kidwai, R. Venkataramanan and B. Dave, J. Heterocyclic Chem., 2002, 39,1045.

38. G. Welsh, The Development and Commercial Implementation of $100 \%$ Carbon Dioxide as an Environmentally friendly Blowing Agent for the Polystyrene Foam Sheet Packaging Market, a proposal submitted to the Presidential Green Chemistry Challenge Awards Program, 1996. Website at www.epa.gov/greenchemistry.

39. J. O. Metzger, Angew. Chem. Int. Ed., 1998, 37, 2975.

40. R. D. Rogers, S. K. Spear, J. G. Huddeston, A. E. Visser, R. P. Swalloski and W. M. Reichert, 'Green Chemistry and Ionic Liquids : Synergies and Ironies',
CHEMRAWN XIV, Colorado, 2001, June 10th-16th.

41. C. A. Eckert, R. Glaeser and J. S. Brown, 'Tuning of Chemical Reactions with Expanded Solids', Proceeding of the fifth conference of supercritical fluids and their applications, Verona, Italy, 1999.

42. J. B. Jones, Tetrahedron, 1986, 42, 3351.

43. C. S. Chen and C. J. Sih, Angew. Chem. Int. Ed., 1989, 28, 695.

44. D. C. Humber, S. B. Laing and G. G. Weingarten, U. S. 4284767,1981 (Chem. Abst., 1980, 93, 46694).

45. A. Corma, Chem. Rev., 1995, 95, 559.

46. H. A. Zahalka and Y. Sasson, Synthesis, 1986, 763.

47. S. C. DeVito and R. L. Garrett, "Designing Safer Chemicals : Green Chemistry and Pollution Prevention", American Chemical Society, 1996.

48. P. Tundo, F. Trost and G. Moraglio, J. Chem. Soc., Perkin Trans. 1, 1989, 1070.

49. T. J. Collins, Science, 2000, 291.

50. V. K. Ahluwalia and M. Kidwai, "New Trends in Green Chemistry", Anamaya Publishers, New Delhi, 2003.

51. R. Narayan, Abstract Papers, 228th ACS National Meeting. Philadelphia, PA, United States, August 22-26, 2004, ACS, Washington, D.C.

52. L. R. Lynel, C. E. Wyman and T. U. Gemgross, Biocommodity Engineering Biotechnol Prog., 1999, 15, 777 .

53. G. Kumar, J. F. Bristow, P. J. Smith and G. F. Payne, Polymer, 2000, 41, 2157.

54. K. M. Draths and J. W. Frost, "Improving the environment through process changes and products substitution, In Green Chemistry : Frontiers in Benign Chemical Syntheses and Processes, 1999, Chap. 9.

55. N. W. Y. Ho, Z. Chen, A. P. Brainard and M. Sedlak, "Engineered Saccharomyces Yeast for Conversation of Cellulosic Biomass to Environmentally Friendly Ethanol", Green Chemical Synthesis \& Processes ACS, 2000, Chap. 12.

56. M. Chong, E. B. Lopkovsky and G. W. Coates, J. Am. Chem. Soc., 1998, 120, 11018.

57. Zujang, M. Henze, T. Curtis, R. Schertenleib and L. L. Beal, Water Science \& Technology : A Journal of International Association on Water Pollution Research, 2004, 49, 1.

58. T. Sarbu, T. Styraner and E. J. Beckman, Nature, $2000,405,165$. 
